Check for updates

Cite this: Mater. Adv., 2021, 2, 3906

Received 2nd October 2020,

Accepted 29th April 2021

DOI: 10.1039/d0ma00756k

rsc.li/materials-advances

\section{Amplified spontaneous emission from oligo( $p$-phenylenevinylene) derivatives $\dagger$}

\author{
Masashi Mamada, (D) *abc Hajime Nakanotani (D) ab and Chihaya Adachi (D) *abcd
}

\section{Introduction}

Organic lasers have had a long history since the first demonstration of the dye laser in $1966 .{ }^{1}$ Research and development has been extended to solid-state lasers, with the potential of innovative optoelectronic applications. ${ }^{2-4}$ Although organic semiconductor laser devices that enable light amplification under electrical pumping have been studied for several decades, they have not been realized until very recently. ${ }^{5,6}$

The gain media for organic solid-state lasers can be classified into two main classes: amorphous films of small molecules and polymers, and organic crystals..$^{7-14}$ Amorphous films are compatible with organic light-emitting diode (OLED) structures; therefore, they are important for the development of organic semiconductor laser diodes (OSLDs). ${ }^{5}$ Single crystals have several advantages, such as higher mobilities, light outcoupling, and better stabilities based on long-range molecular order. They can also be used in light-emitting field-effect transistors (LEFETs). ${ }^{6}$ For both classes, the molecular structures of the laser materials involve common basic $\pi$-electronic systems, such as simple oligo-aromatics and oligomeric

\footnotetext{
${ }^{a}$ Center for Organic Photonics and Electronics Research (OPERA),

Kyushu University, Fukuoka 819-0395, Japan

E-mail:mamada@opera.kyushu-u.ac.jp, adachi@cstf.kyushu-u.ac.jp

${ }^{b}$ JST, ERATO, Adachi Molecular Exciton Engineering Project c/o Center for Organic

Photonics and Electronics Research (OPERA), Kyushu University, Nishi,

Fukuoka 819-0395, Japan

${ }^{c}$ Academia-Industry Molecular Systems for Devices Research and Education Center (AIMS), Kyushu University, Nishi, Fukuoka 819-0395, Japan

${ }^{d}$ International Institute for Carbon Neutral Energy Research (WPI-I2CNER),

Kyushu University, Nishi, Fukuoka 819-0395, Japan

$\dagger$ Electronic supplementary information (ESI) available: Synthesis, characterization, computational, photophysical, electrochemical and thin-film transistor data. CCDC 2034947-2034953. For ESI and crystallographic data in CIF or other electronic format see DOI: 10.1039/d0ma00756k
}

phenylenevinylenes. ${ }^{15-24}$ Therefore, fundamental knowledge of the relationship between basic structure and properties is necessary to develop a wide variety of laser materials.

Stilbene is an important moiety that is used in numerous solid-state laser materials. Stilbene derivatives with carbazole rings form amorphous films with excellent laser properties, $^{25-28}$ which were key to the success of quasicontinuous-wave lasers and electrically pumped lasers. ${ }^{5,29,30}$ In addition, poly ( $p$-phenylenevinylene) (PPV) is a notable backbone for deriving excellent laser materials. ${ }^{31-33}$ Meanwhile, high-quality single crystals can easily be made from 1, 4-distyrylbenzene (DSB/2PV/P3V2, 1a in Fig. 1). ${ }^{34-36}$ Thus, there have been many derivatives based on 1a that have several substituents, such as cyano and alkoxy groups, which control crystal-packing structures. ${ }^{11,14}$ In particular, there are many reports on compounds having cyano groups on the vinyl groups (1b and 1c). ${ }^{37-53}$ Both compounds exhibit polymorphism with blue and green emission. The blue phase of $\mathbf{1 b}$ and $\mathbf{1 c}$ has a herringbone packing structure similar to $\mathbf{1 a}$, which results in similar emission maxima in the blue region. These are also known to have lasing capabilities. On the other hand, the green phases have strong $\pi$-stacking structures that exhibit excimerlike emission. Therefore, they have high mobilities in single-crystal LEFETs but exhibit no light amplification. The relationship between laser properties and crystal-packing structures has been well-documented in review papers. ${ }^{12,14}$

Compared with P3V2 derivatives, there is a very limited number of $\pi$-extended molecules except for PPV-based polymers. ${ }^{19,36,54-56}$ Because the net-gain cross-section for lasers is a function of the stimulated emission cross-section $\left(\sigma_{\mathrm{em}}\right)$ and the population inversion density $(\Delta N)$, a large transition dipole moment in a molecule can reduce the threshold energy for light amplification. A longer $\pi$-conjugation length increases the oscillator strength of an electronic transition, which is 

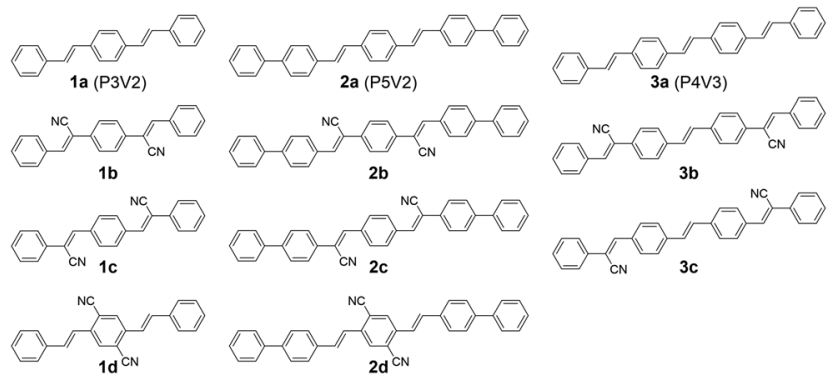

3c

Fig. 1 Chemical structures of phenylenevinylene small molecules.

proportional to the square of the transition dipole moment. Therefore, extended $\pi$-structures are an effective strategy to improve laser properties. Nevertheless, the $\pi$-conjugation length of 1a is relatively short compared with those of excellent amorphous-type laser materials. ${ }^{20}$

In this work, we investigated several oligo( $p$-phenylenevinylene) derivatives (Fig. 1). The laser properties are expected to be improved for the P5V2 and P4V3 series relative to those of the P3V2 derivatives since $\mathbf{3 a}$ had a better amplified spontaneous emission (ASE) threshold than 1a. ${ }^{36}$ However, it is more difficult to predict packing structures that greatly affect laser properties. Although linear oligo-aromatics generally have a herringbone packing because of the low $\mathrm{C} / \mathrm{H}$ ratio, ${ }^{57}$ cyanosubstituted compounds should have more complex intermolecular interactions that can form various arrangements, including $\pi$-stacking structures. Here, their crystal structures and photophysical properties are presented.

\section{Results and discussion}

The compounds 1d, 2a, 2d and 3a were synthesized with the Wittig-Horner reaction, and $\mathbf{1 b}, \mathbf{1 c}, \mathbf{2 b}, \mathbf{2 c}, \mathbf{3 b}$ and $3 \mathbf{c}$ were synthesized by the Knoevenagel reaction. Both reactions produced good yields (Methods S1 in the ESI $\dagger$ ). ${ }^{58}$ The compounds were purified by vacuum sublimation and their crystals were grown via sublimation under a nitrogen flow. The sublimation temperatures were $300-350{ }^{\circ} \mathrm{C}$ for the P5V2 series and 270-300 ${ }^{\circ} \mathrm{C}$ for the $\mathrm{P} 4 \mathrm{~V} 3$ series.

The absorption and photoluminescence (PL) spectra for these compounds in chloroform solutions and in the crystalline form are shown in Fig. 2. In general, because of extended $\pi$-conjugation, the $\mathrm{P} 5 \mathrm{~V} 2$ and $\mathrm{P} 4 \mathrm{~V} 3$ series spectra were at longer wavelengths than those of the P3V2 series. Although the absorption maxima of $\mathbf{1} \mathbf{b}, \mathbf{2} \mathbf{b}$, and $\mathbf{3} \mathbf{b}$ in solution appear at shorter wavelengths relative to those of $\mathbf{1 a}, \mathbf{2 a}$ and $3 \mathbf{a}$, respectively, the onset of absorption is in the order $\mathbf{a}<\mathbf{b}<\mathbf{c}<\mathbf{d}$. Hence, the optical energy gap $\left(E_{\mathrm{g}}^{\mathrm{opt}}\right)$ decreases in order from a to d, which agrees well with the calculations (Methods S2 and Tables S1-S3 in the ESI $\dagger$ ). The Stokes shifts for $\mathbf{1 b}, \mathbf{1 c}, \mathbf{2 b}$, and 2c are larger than those for $\mathbf{1 d}$ and $\mathbf{2 d}$, as indicated by the calculations (Table S3, ESI $\dagger$ ), and the $0-0$ peaks for $\mathbf{b}$ and $\mathbf{c}$ have a gentle slope relative to those for a and $\mathbf{d}$. These results might be related to the high degree of rotational motion of the vinyl groups that were substituted with cyano groups in $\mathbf{b}$ and $\mathbf{c}$. Such compounds are known to exhibit aggregation-induced emission enhancement (AIEE) and crystallization-induced emission enhancement (CIEE). ${ }^{59}$ Thus, the PL quantum yields $\left(\Phi_{\mathrm{PL}}\right)$ in solution are very low for $\mathbf{b}$ and $\mathbf{c}$, although 2c was slightly emissive (Table 1). The radiative rate constant $\left(k_{\mathrm{r}}\right)$ values for $\mathbf{1 a}$, $2 \mathrm{a}$, and $3 \mathrm{a}$ in solution are very high at $7.3 \times 10^{8}, 1.1 \times 10^{9}$, and $7.7 \times 10^{8} \mathrm{~s}^{-1}$, respectively, which were consistent with the conjugation lengths and the calculated oscillator strengths.

The photophysical properties in the crystal are distinctively different from those in solution because the molecular geometries are fixed in the solid state and the intermolecular interactions greatly affect their electronic structures. Single-crystal $\mathrm{X}$-ray structure analysis is thus the best way to understand the relationship between solid-state optoelectronic properties and structures. Crystal structures have been reported for 1a (CCDC $1181381,{ }^{34}$ and $921998^{35}$ ), the $\mathbf{1 b}$ blue phase (CCDC $1247728,{ }^{37}$ $799014,{ }^{38} 892284,{ }^{39}$ and $1473570,{ }^{40}$ note that these structures are substantially the same), the $\mathbf{1 b}$ green phase (CCDC $892287,{ }^{39}$ and $1473571^{40}$ ), the 1c blue phase (CCDC 815708), ${ }^{46}$ the 1c green phase polymorph 1 (CCDC 860278), ${ }^{48}$ and the 1c green phase polymorph 2 (CCDC 1542079). ${ }^{52}$ The crystal structure of $2 \mathbf{a}$ was reported, ${ }^{54}$ but no CCDC number is available. Hence, we solved the crystal structures for $\mathbf{1 d}, \mathbf{2 b}, \mathbf{2 c}, \mathbf{2 d}, \mathbf{3 a}, \mathbf{3 b}$, and 3c (Fig. 3 and Tables S4-S10, ESI $\dagger$ ). Judging from their emission spectra, the crystals for these compounds are unlikely to exhibit polymorphism. The emission properties of the crystals are also summarized in Table 1. Significant differences in the crystal structures of these compounds occur in the packing motifs, that is, herringbone or $\pi$-stacking. Note that crystals of these compounds are often referred to as $\mathrm{H}$ - and J-aggregates for the specific arrangement of two molecules in the stacking direction. However, the molecules have three-dimensional interactions, complicating the dipole couplings. The excitation spectra for these crystals (Fig. S1, ESI $\dagger$ ) indicate that the classification is difficult because 1a, which is often described as a $\mathrm{H}$-aggregate with herringbone packing, ${ }^{12}$ might exhibit a red-shifted absorption in the crystal compared with that in solution. Therefore, we avoid mentioning $\mathrm{H}$ - and J-aggregates for the new compounds. Further discussion should be reported in the future, with the combination of theoretical calculations and full experimental data, including optical spectra and crystal structures.

The compounds without cyano groups (1a, 2a, and 3a) had typical herringbone packing with nearly flat stilbene structures and similar $k_{\mathrm{r}}$ values $\left(>2 \times 10^{8} \mathrm{~s}^{-1}\right)$. Compounds $\mathbf{1 b}$ and $\mathbf{1 c}$, both with polymorphisms, have blue-emissive herringbone packing and green-emissive $\pi$-stacking structures. The emission wavelengths of the blue phases are similar to those of 1a, although 1b and 1c have twisted conformations. The large bathochromic shifts of the emission with broad spectral shapes observed for the $\pi$-stacking molecules are attributed to excimerlike features. The cyano-vinylene groups are overlapped with phenyl groups in the $\pi$-stacking, which enables intermolecular charge transfer (CT). For 1d, the 1,4-dicyanobenzene apparently inhibited herringbone packing. Thus, the crystal packing is 


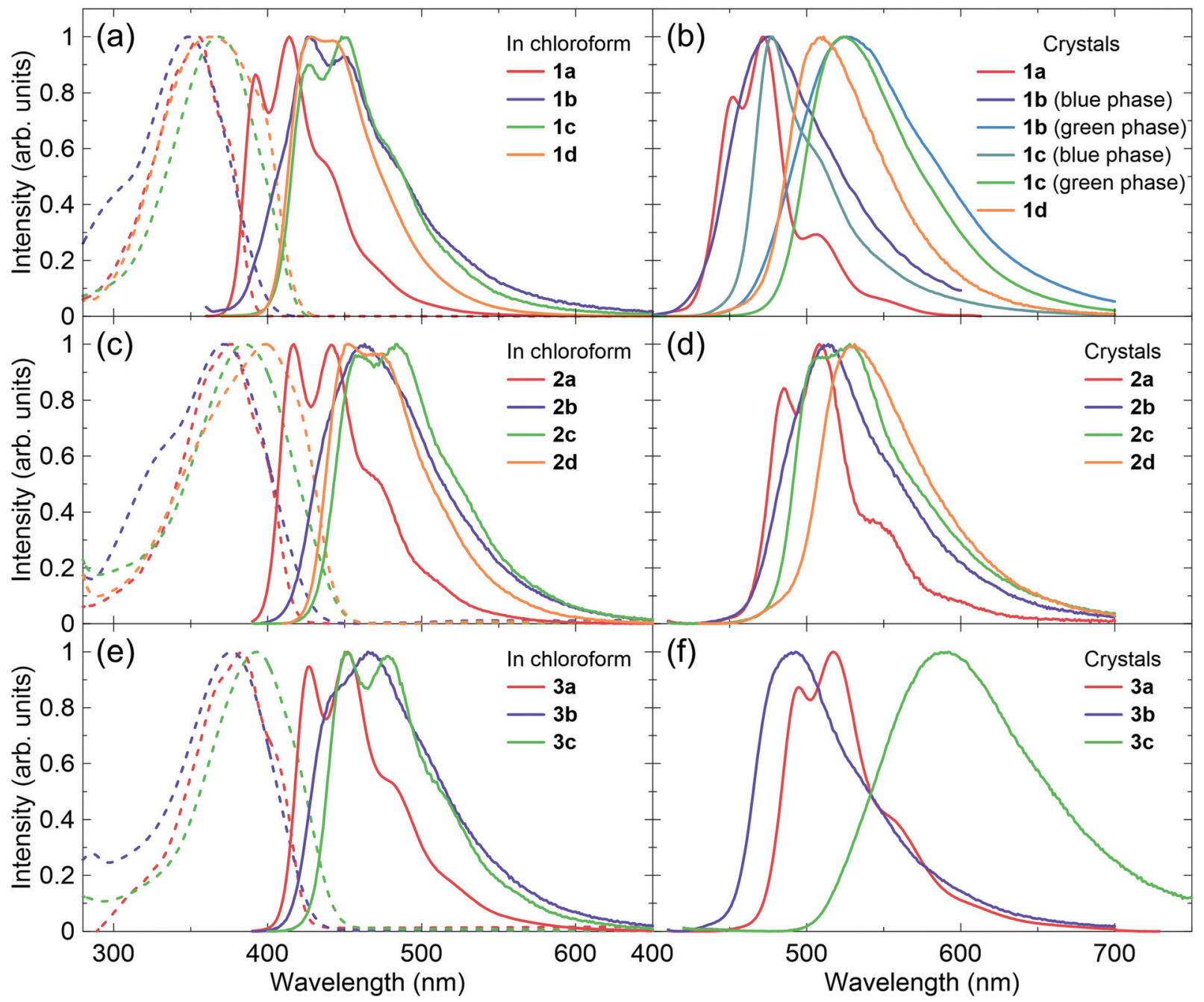

Fig. 2 Ultraviolet-visible absorption (dashed lines) and emission (solid lines) spectra for (a) $\mathbf{1 a - 1 d}$ in chloroform, (b) crystalline 1a-1d, (c) $\mathbf{2 a - 2 d}$ in chloroform, (d) crystalline $\mathbf{2 a - 2 d}$, (e) $\mathbf{3 a - 3 c}$ in chloroform, and (f) crystalline $\mathbf{3 a - 3 c}$.

relatively similar to the green phases of $\mathbf{1 b}$ and $\mathbf{1 c}$, with strong $\pi$-stacking. The emission properties are also similar.

Compounds $\mathbf{2 b}$ and $\mathbf{2 c}$ have herringbone packing, but did not form $\pi$-stacking structures. This can be explained by the non-planar biphenyl rings, which prevent interactions between the cyano-vinylene groups and the phenyl rings, while still facilitating herringbone packing between the biphenyl rings. The emission wavelengths of $\mathbf{2 b}$ and $\mathbf{2 c}$ are not significantly red-shifted from those of $2 \mathbf{a}$. The values of $\Phi_{\mathrm{PL}}$ and $k_{\mathrm{r}}$ are high and are expected to exhibit ASE. Similar to 1d, the 1, 4-dicyanobenzene structure in 2d hinders the herringbone packing, while biphenyl rings also limit $\pi$-stacking. As a result, 2d has a hybrid structure of herringbone and $\pi$-stacking. The excimer features are not strong because the 1,4-dicyanobenzene rings are mainly overlapped between themselves, which results in a small bathochromic shift compared with 2a-2c. However, the emission decay lifetime is relatively long and $k_{\mathrm{r}}$ was less than $1 \times 10^{8} \mathrm{~s}^{-1}$.

Interestingly, compounds $\mathbf{3 b}$ and $\mathbf{3} \mathbf{c}$ had very different features. The $\mathbf{3} \mathbf{b}$ emission was blue-shifted from that of $\mathbf{3 a}$, but the $\mathbf{3 c}$ emission was largely red-shifted. The $\mathbf{3 c}$ crystal included two types of $\pi$-stacking: single column stacking and two molecular layers with slipped $\pi$-stacking between the columns. The broad orange emission implies extensive excimer formation, probably in the molecules forming the column stacking. The $\Phi_{\mathrm{PL}}$ of the $\mathbf{3 b}$ crystal is relatively high and that of $3 \mathbf{c}$ is moderate, although the fluorescence in solution was very weak for both compounds. Thus, these compounds are considered to be CIEE materials, such as $\mathbf{1 b}$ and 1c. The AIEE characteristics were also examined in mixed tetrahydrofuran (THF)/water solvents (Fig. 4). The suspension in solutions with higher water content includes various aggregated states, which may be different from the bulk crystals. Compound $\mathbf{3 b}$ had AIEE characteristics, although the $\Phi_{\mathrm{PL}}$ even in $90 \%$ water was lower than that in the crystals. The 3c spectra were clearly shifted with increasing water content up to $70 \%$. However, the $\Phi_{\mathrm{PL}}$ were almost constant. Therefore, the highly ordered molecular arrangements are expected to be efficiently emissive. The values of $k_{\mathrm{r}}$ for the $\mathbf{3} \mathbf{b}$ crystal was slightly higher than that of the blue-emissive $\mathbf{1 b}$ crystal. This is attributed to the larger 
Table 1 Photophysical and amplified spontaneous emission (ASE) properties in chloroform and in crystals

\begin{tabular}{|c|c|c|c|c|c|c|c|c|}
\hline Compound & Condition & $\lambda_{\mathrm{abs}}[\mathrm{nm}]$ & $\lambda_{\mathrm{PL}}[\mathrm{nm}]$ & $\Phi_{\mathrm{PL}}^{a}[-]$ & $\tau[\mathrm{ns}]$ & $k_{\mathrm{r}} / 10^{8}\left[\mathrm{~s}^{-1}\right]$ & $E_{\mathrm{th}}^{\mathrm{ASE}}\left[\mu \mathrm{J} \mathrm{cm}{ }^{-2}\right]$ & $\lambda_{\mathrm{ASE}}[\mathrm{nm}]$ \\
\hline & Crystal $^{b}$ & - & 452,472 & 0.85 & 2.9 & 2.9 & $18 \pm 6$ & 466 \\
\hline \multirow[t]{2}{*}{$1 b$} & Chloroform & 348 & 426,449 & $<0.01$ & $-^{c}$ & - & - & - \\
\hline & Crystal (green) & - & 526 & 0.36 & $6.1,14$ & 0.36 & No ASE & No ASE \\
\hline \multirow[t]{2}{*}{$1 \mathrm{c}$} & Chloroform & 368 & 426,448 & $<0.01$ & $-^{c}$ & - & - & - \\
\hline & Crystal (blue) & - & 477 & 0.55 & $1.6,8.3$ & 3.2 & - & - \\
\hline & Crystal & - & 511 & 0.64 & 18 & 0.36 & No ASE & No ASE \\
\hline \multirow[t]{2}{*}{$2 \mathbf{a}$} & Chloroform & 377 & 417,441 & 0.93 & 0.82 & 11.3 & - & - \\
\hline & Crystal & - & 485,508 & 0.58 & $1.5,3.0$ & 2.4 & $18 \pm 2$ & 515 \\
\hline \multirow[t]{2}{*}{$2 b$} & Chloroform & 371 & 463 & 0.01 & $-^{c}$ & - & - & - \\
\hline & Crystal & - & 514 & 0.67 & $1.4,2.6$ & 3.6 & $7.4 \pm 2$ & 513 \\
\hline \multirow[t]{2}{*}{$2 \mathrm{c}$} & Chloroform & 385 & 457,484 & 0.16 & 0.45 & 3.5 & - & - \\
\hline & Crystal & - & 510,528 & 0.71 & $2.1,3.7$ & 2.4 & 12 and 8.5 & 504 and 531 \\
\hline $3 \mathbf{b}$ & Crystal & - & 493 & 0.63 & $0.7,1.8$ & 3.7 & $7.2 \pm 2$ & 495 \\
\hline \multirow[t]{2}{*}{$3 \mathrm{c}$} & Chloroform & 393 & 450,478 & 0.02 & $-^{c}$ & - & - & - \\
\hline & Crystal & - & 592 & 0.30 & $7.7,21$ & 0.17 & No ASE & No ASE \\
\hline
\end{tabular}

${ }^{a}$ Absolute PL quantum yield evaluated using an integrating sphere. ${ }^{b}$ Taking from the literature (ref. 36 ). ${ }^{c}$ Could not be determined because of the measurement limit.

(a)

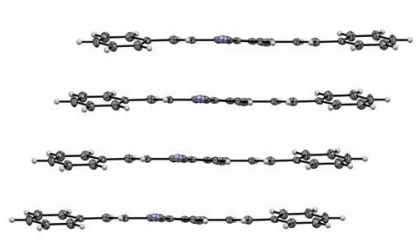

(e)

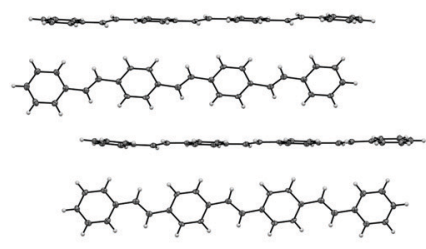

(b)

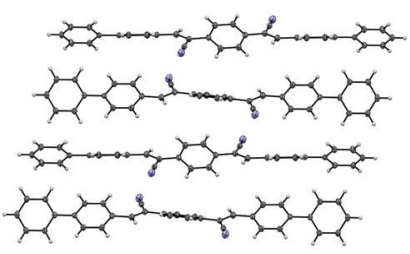

(c)

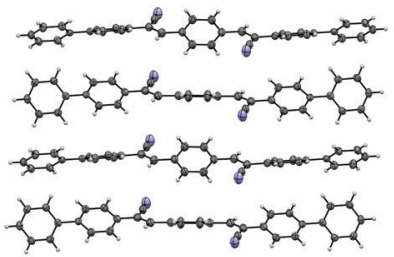

(d)

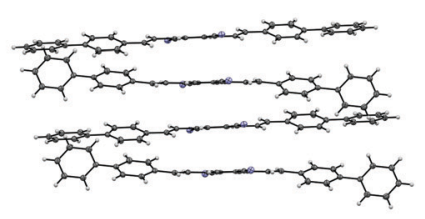

(f)

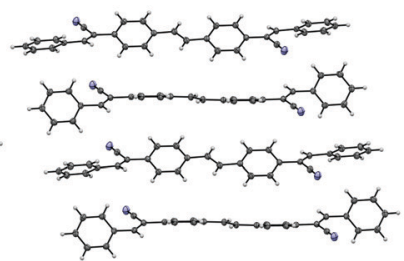

(g)

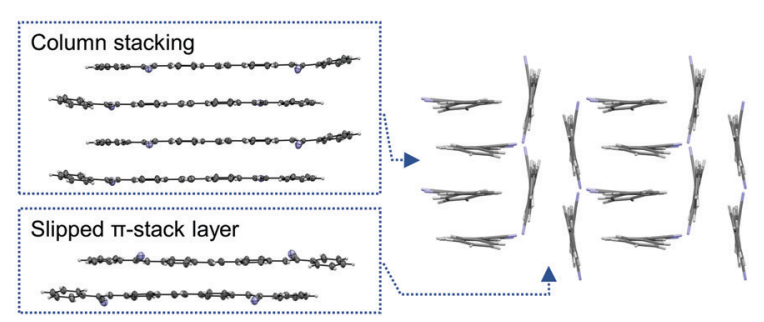

Fig. 3 Crystal structures of (a) $\mathbf{1 d}$, (b) $\mathbf{2 b}$, (c) $\mathbf{2 c}$, (d) $\mathbf{2 d}$, (e) $\mathbf{3 a}$, (f) $\mathbf{3 b}$, (g) $\mathbf{3 c}$.

oscillator strength. The value of $k_{\mathrm{r}}$ for the $3 \mathbf{c}$ crystal was expected to be low because of its relatively long fluorescence lifetime based on excimer formation.

Fig. 5, 6 and Fig. S2 (ESI $\dagger$ ) show ASE characteristics for these crystals. The blue-emissive crystals of $\mathbf{1 b}$ and $\mathbf{1 c}$ are reported to exhibit ASE with the extremely high thresholds of

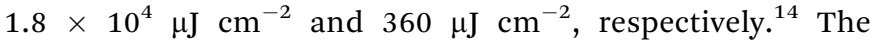
thresholds are often increased in the low-quality crystals. In general, sublimation under a nitrogen flow forms betterquality crystals compared to solution-based techniques. The oligo( $p$-phenylenevinylene) derivatives tend to form large single crystals. In many cases, thin platelet crystals with thicknesses ranging from several hundred nanometres to several micrometres are favourable for ASE measurements and LEFET fabrications. Fortunately, large enough crystals of blue-emissive $\mathbf{1 b}$ could be obtained, although the larger green-emissive crystals were the main products. An ASE threshold as low as $18 \mu \mathrm{J} \mathrm{cm}^{-2}$ can be observed for the blue-phase crystal (Fig. S2, ESI $\dagger$ and Table 1). Meanwhile, the 1c blue-emissive crystals were very small, which hindered the determination of a reliable ASE threshold with our apparatus. Note that the green-emissive crystals with $\pi$-stacking structures did not exhibit ASE for $\mathbf{1 b}$ and 1c up to $200 \mu \mathrm{J} \mathrm{cm} \mathrm{cm}^{-2}$. 

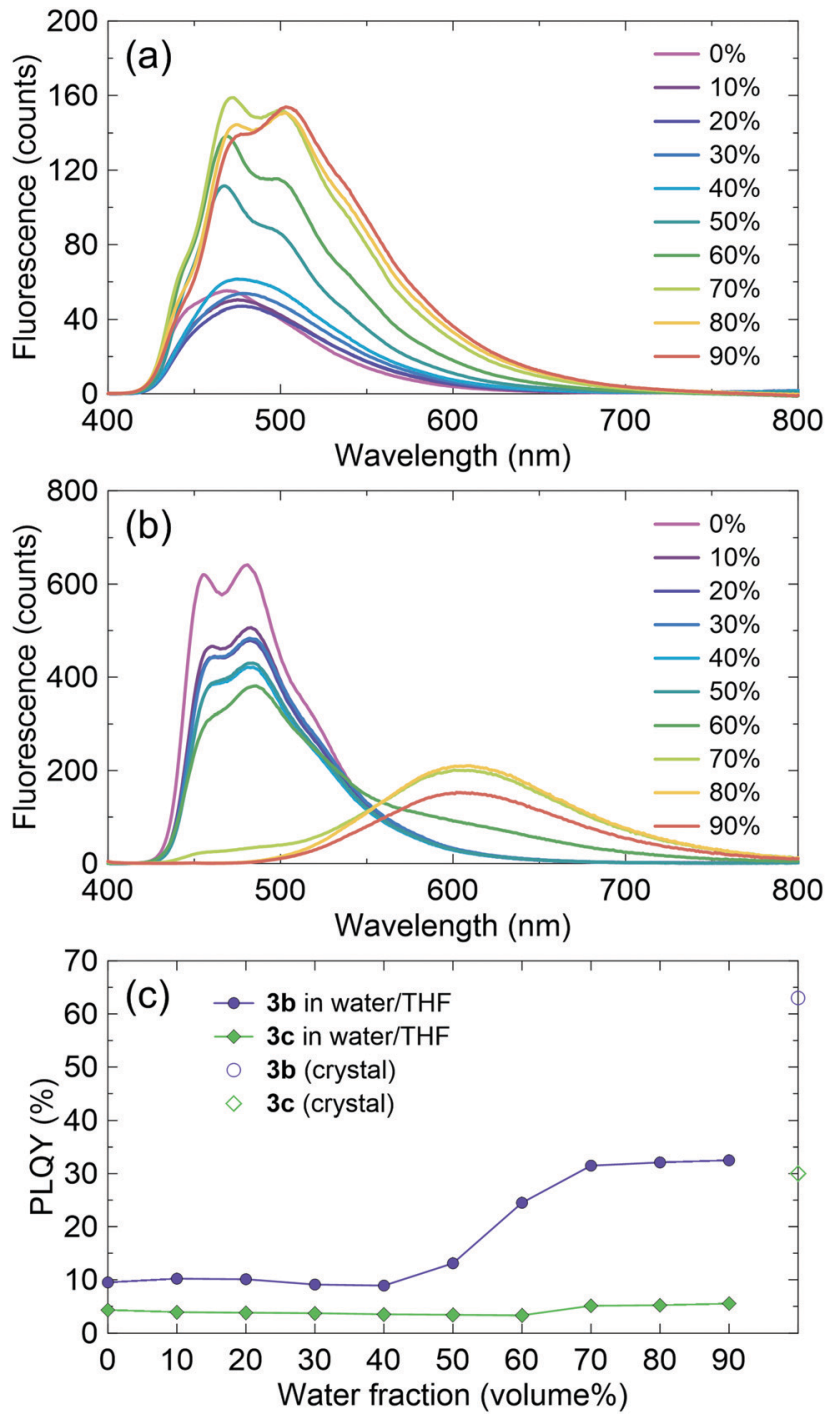

Fig. 4 Emission spectra of (a) $3 \mathbf{b}$ and (b) $3 c$ in $x \%$-water/(100 - x)\%tetrahydrofuran (THF) mixed solvent. The concentration was fixed at $3.0 \times 10^{-5} \mathrm{M}$. (c) Water fraction dependence of the $\Phi_{\mathrm{PL}}$, and the $\Phi_{\mathrm{PL}}$ in the crystal.

The ASE for $\mathbf{2 a}$ and $\mathbf{2 b}$ were observed at $c a .515 \mathrm{~nm}$, which is nearly the same as the peaks of stimulated emission cross-section spectra (Fig. 5). The ASE thresholds of $2 \mathbf{a}$ and $2 \mathbf{b}$ were $18 \mu \mathrm{J} \mathrm{cm}^{-2}$ and $7.4 \mu \mathrm{J} \mathrm{cm}^{-2}$, respectively. Similarly, the thresholds for $3 \mathbf{a}$ and $\mathbf{3 b}$ were $11 \mu \mathrm{J} \mathrm{cm}^{-2}$ and $7.2 \mu \mathrm{J} \mathrm{cm}^{-2}$, respectively. The introduction of electron-withdrawing cyano groups into the compounds with donor units resulted in red-shifted emission, a decrease in $k_{\mathrm{r}}$, and an increase in the ASE thresholds because of increased intramolecular CT character. ${ }^{27}$ However, we have demonstrated improved ASE thresholds for cyano-substituted compounds without strong donor-acceptor interactions. These results indicated that cyanosubstitution paves the way for improving the laser properties of p-phenylenevinylene derivatives, including polymers based on PPV.

The ASE of 2c has two peaks that are apparently different from the others (Fig. 6), but more similar to that of methylsubstituted P3V2, 1,4-bis(4-methylstyryl)benzene. ${ }^{60}$ The results seem to correlate with crystal thicknesses. The thicker crystals
(>1000 nm) had ASE mainly at the lower-energy sub-band at $531 \mathrm{~nm}$ (referred to the 0-2 transition, according to ref. 60). In contrast, the thinner crystals $(\sim 250 \mathrm{~nm})$ had the ASE at the higher-energy sub-band at $504 \mathrm{~nm}$ (referred to the 0-1 transition, according to ref. 60). In addition, the two ASE peaks evolved simultaneously in the moderately thick crystals (300-1000 $\mathrm{nm})$, where the peak at $531 \mathrm{~nm}$ first increased (number 1 in Fig. 6e), then the peak at $504 \mathrm{~nm}$ increased (number 2 in Fig. 6e), while the $531 \mathrm{~nm}$ peak then decreased (number 3 in Fig. 6e). Note that the out-of-plane X-ray diffractions for these crystals excluded polymorphism (Fig. S3, ESI $\dagger$ ). The dual-wavelength ASE has been explained by re-absorption by molecules in the ground state or in excited states. ${ }^{61-63}$ The experimental results for $\mathbf{2 c}$, including the thickness dependence and the different energy behaviours of the two ASE peaks, suggest the same mechanism as that reported previously for the two-transition ASE origin. Because the optical amplifications at $504 \mathrm{~nm}$ and $531 \mathrm{~nm}$ are competitive processes, the $531 \mathrm{~nm}$ intensity decreased with increasing $504 \mathrm{~nm}$ intensity in Fig. 6e when the net gain at $504 \mathrm{~nm}$ became larger than that at $531 \mathrm{~nm}$ with intense excitation. The best thresholds were $12 \mu \mathrm{J} \mathrm{cm}^{-2}$ and $8.5 \mu \mathrm{J} \mathrm{cm}^{-2}$ for the $504 \mathrm{~nm}$ and $531 \mathrm{~nm}$ transitions, respectively.

As expected, the other compounds (1d, 2d, and 3c) with $\pi$-stacking structures did not exhibit ASE. These results also verified that solid-state interactions are very important when developing highly efficient laser materials.

Finally, charge transport properties for $\mathbf{2 a}$ were evaluated and summarized in Table S11 (ESI $\dagger$ ) since the reported mobilities were relatively low $\left(\mu_{\mathrm{h}}=1.6 \times 10^{-4} \mathrm{~cm}^{2} \mathrm{~V}^{-1} \mathrm{~s}^{-1}\right)$ compared with those of $1 \mathrm{a}\left(\mu_{\mathrm{h}}=0.12 \mathrm{~cm}^{2} \mathrm{~V}^{-1} \mathrm{~s}^{-1}\right.$ and $\left.\mu_{\mathrm{e}}=1.3 \times 10^{-2} \mathrm{~cm}^{2} \mathrm{~V}^{-1} \mathrm{~s}^{-1}\right)$ and $3 \mathrm{a}\left(\mu_{\mathrm{h}}=0.12 \mathrm{~cm}^{2} \mathrm{~V}^{-1} \mathrm{~s}^{-1}\right.$ and $\left.\mu_{\mathrm{e}}=0.11 \mathrm{~cm}^{2} \mathrm{~V}^{-1} \mathrm{~s}^{-1}\right) .{ }^{36,54}$ This is certainly attributed to the different types of active media and device configurations: thin-film vs. single-crystal and gold source-drain (S-D) electrodes $v s$. asymmetric gold-calcium S-D electrodes. The single-crystal transistors normally exhibited better performances because of their perfect molecular arrangements that were free of grain boundaries and had minimal defects. ${ }^{64}$ The asymmetric electrodes with different work-functions (gold: 4.5-5.1 eV and calcium: 2.9-3.0 eV) ease the injection of both hole and electron carriers. ${ }^{65}$ Therefore, we fabricated 2a-based single-crystal transistors using gold-calcium electrodes. Both p- and n-type characteristics were clearly observed with saturated mobilities of $\mu_{\mathrm{h}}=0.05 \pm 0.01 \mathrm{~cm}^{2} \mathrm{~V}^{-1} \mathrm{~s}^{-1}$ and $\mu_{\mathrm{e}}=0.25 \pm 0.06 \mathrm{~cm}^{2} \mathrm{~V}^{-1} \mathrm{~s}^{-1}$ for three devices (Fig. 7). Although the hole mobility was slightly lower than those in 1a and 3a, it was significantly improved compared to those in the thin-film devices. In addition, high electron mobility was observed owing to effective carrier injection from the calcium electrode. These high mobilities suggest considerable potential of $p$-phenylenevinylene derivatives for electrically pumped lasers. Unfortunately, the devices of the cyanoderivatives such as $\mathbf{2 d}$ and $\mathbf{3} \mathbf{b}$ did not show improved performances. In addition, the $3 c$ crystals are needles, which differ from the thin-platelets of the other compounds; this makes device fabrication difficult. 

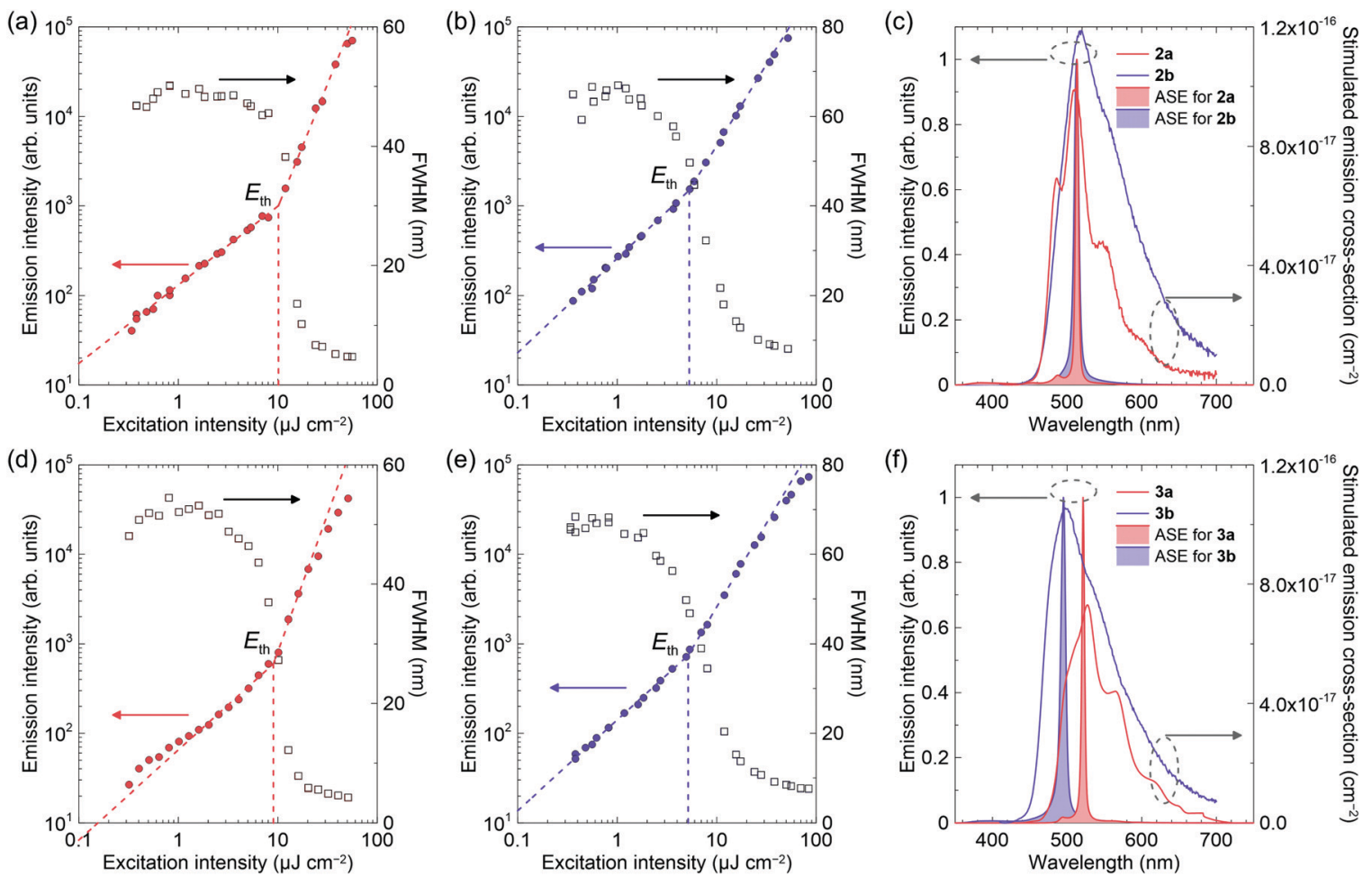

Fig. 5 Output photoluminescence (PL) intensity and full width at half maximum (FWHM) values from edges of the crystals of (a) $\mathbf{2 a}$, (b) $\mathbf{2} \mathbf{b}$, (d) $\mathbf{3} \mathbf{a}$, (e) $\mathbf{3} \mathbf{b}$. The stimulated cross-section spectra and PL spectra above the amplified spontaneous emission (ASE) threshold for (c) $\mathbf{2} \mathbf{a}$ and $\mathbf{2} \mathbf{b}$, and (f) $\mathbf{3} \mathbf{a}$ and $\mathbf{3} \mathbf{b}$.

(a)

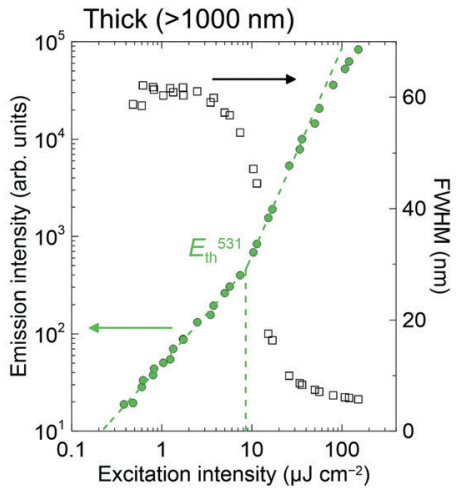

(d)

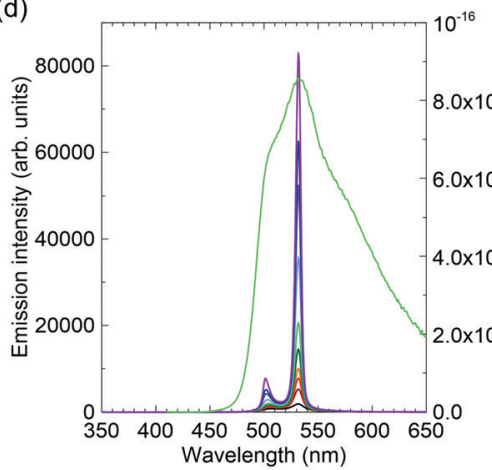

(b)
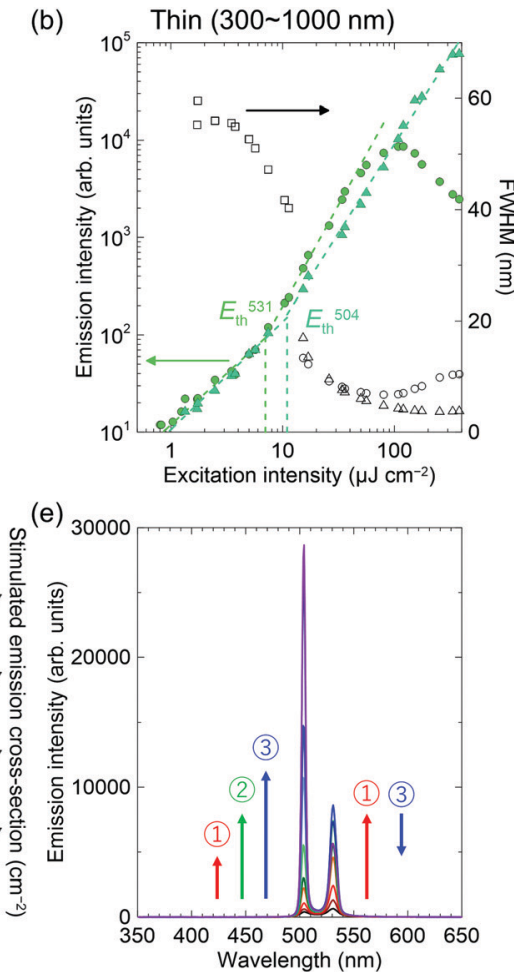

(c)

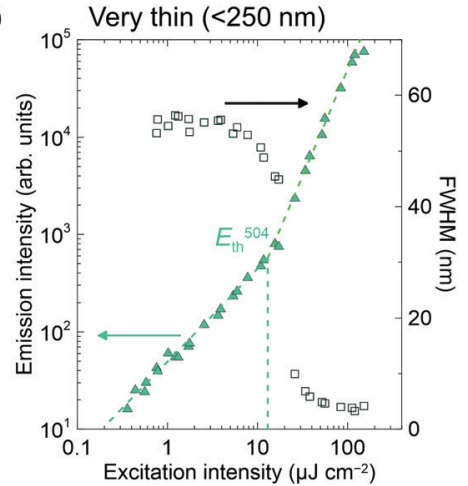

(f)

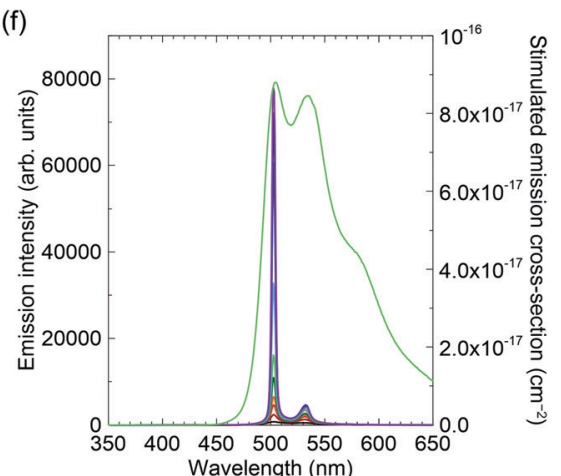

Fig. 6 Output photoluminescence (PL) intensity and full width at half maximum (FWHM) values and PL spectra at different excitation energies from the edges of $\mathbf{2 c}$ crystals. Amplified spontaneous emission (ASE) behaviour for (a and d) thick crystals ( $>1000 \mathrm{~nm}$ ), (d and e) thin crystals (300-1000 nm), and (c and f) very thin crystals $(<250 \mathrm{~nm})$. 
(a)

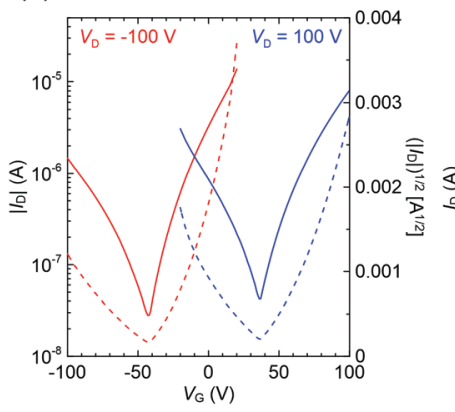

(b)

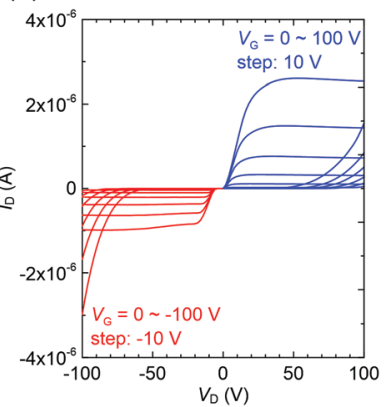

Fig. 7 (a) Transfer and (b) output characteristics of a single-crystal fieldeffect transistor (FET) for $\mathbf{2} \mathbf{b}$ with gold-calcium source-drain electrodes. The channel length and width are ca. $100 \mu \mathrm{m}$ and ca. $300 \mu \mathrm{m}$, respectively.

\section{Conclusions}

In this study, we developed several $\pi$-extended stilbene derivatives to increase the understanding of structure-property relationships. The crystal structures were fully investigated and classified according to herringbone and $\pi$-stacking structures. The $k_{\mathrm{r}}$ values were strongly related to the packing motifs, and high values up to $3.7 \times 10^{8} \mathrm{~s}^{-1}$ were achieved for compounds with herringbone packing. Since the biphenyl groups prevent $\pi$-stacking, it would be useful to design the laser materials. On the other hand, it is more difficult to predict the crystal packing for the compounds with cyano groups on the vinyl groups. Compounds with $\pi$-stacking structures did not exhibit ASE, while clear ASE peaks were observed for those with herringbone packing. The ASE thresholds were mostly lower for the $\pi$-extended compounds and were as low as $7.2 \mu \mathrm{J} \mathrm{cm}{ }^{-2}$ with cyano substitutions. These results give a systematic insight into light amplification in the single crystals.

\section{Experimental section}

\section{General}

Commercially available materials were used as received from the suppliers for the synthesis (Table S12, ESI $\dagger$ ). Details of instruments and physical measurements are given in Table S13 $(\mathrm{ESI} \dagger)$.

\section{Materials synthesis and characterization}

The synthesis procedures and characterization data of materials used in this study are described in the ESI $\dagger$ (Methods S1) and NMR spectra are given in Data S1.

\section{Quantum calculations}

Details of the calculations are described in the ESI $\dagger$ (Methods S2 and Tables S1-S3).

\section{X-Ray structure analysis}

Single crystals suitable for X-ray analysis were grown by slow sublimation under nitrogen flow. X-Ray diffraction data were collected on a Rigaku Saturn724 diffractometer with Mo-K $\alpha$ radiation $(\lambda=0.71075 \AA)$ at $123 \mathrm{~K}$ for $2 \mathbf{b}, 3 \mathbf{b}$ and $3 \mathbf{c}$, a Rigaku

R-AXIS RAPID diffractometer with $\mathrm{Cu}-\mathrm{K} \alpha$ radiation $(\lambda=1.54187 \AA)$ at $183 \mathrm{~K}$ for $2 \mathrm{c}$, and a Rigaku AFC HyPix-6000 diffractometer with Mo-K $\alpha$ radiation at $100 \mathrm{~K}$ for $\mathbf{1 d}, \mathbf{3 a}$, and $\mathbf{2 d}$. All non-hydrogen atoms were refined anisotropically. The positions of all hydrogen atoms were calculated geometrically and refined as a riding model. CCDC 2034947-2034953. $\dagger$

\section{ASE measurements}

The thin flexible crystals were grown by sublimation under nitrogen flow. The crystal samples were placed on the cleaned quartz substrate. ASE properties were characterized by optically pumping with a randomly polarized nitrogen gas laser (KEN2020, Usho Optical Systems Co., Ltd) at an excitation wavelength of $337 \mathrm{~nm}$ with a $0.8 \mathrm{~ns}$ pulse (operating frequency of $10 \mathrm{~Hz}$ ). The input laser beam was focused into a stripe with dimensions of $c a .0 .5 \mathrm{~cm} \times 0.1 \mathrm{~cm}$ using a cylindrical lens. Neutral density filters were used to adjust excitation intensity. ASE measurements were performed under a nitrogen atmosphere to prevent degradation. Output light emission from the edge of the sample was collected into an optical fiber connected to a spectrometer (Hamamatsu Photonics PMA-11). ASE thresholds were identified from the plot of output versus input intensity. The thresholds of absorbed energy density were not calculated because absorbance of a single crystal sample is difficult to measure. Reproducibility was confirmed by measuring at least five different samples.

\section{Conflicts of interest}

There are no conflicts to declare.

\section{Acknowledgements}

We thank Ms K. Kusuhara and Ms N. Nakamura for the characterization of materials, and $\mathrm{Mr}$ T. Matsumoto for the measurements of X-ray single crystal analysis. This work was financially supported by JST ERATO Grant Number JPMJER1305, JSPS KAKENHI Grant Number $19 \mathrm{H} 02790$ and 20K21227, The Murata Science Foundation and the JSPS Core-to-Core Program.

\section{Notes and references}

1 F. P. Schäfer, W. Schmidt and J. Volze, Appl. Phys. Lett., 1966, 9, 306-309.

2 N. Tessler, G. Denton and R. Friend, Nature, 1996, 382, 695-697.

3 F. Hide, M. A. DiazGarcia, B. J. Schwartz, M. R. Andersson, Q. B. Pei and A. J. Heeger, Science, 1996, 273, 1833-1836.

4 M. D. McGehee and A. J. Heeger, Adv. Mater., 2000, 12, 1655-1668.

5 A. S. D. Sandanayaka, T. Matsushima, F. Bencheikh, S. Terakawa, W. J. Potscavage, C. Qin, T. Fujihara, K. Goushi, J.-C. Ribierre and C. Adachi, Appl. Phys. Express, 2019, 12, 061010. 
6 T. Kanagasekaran, H. Shimotani, K. Kasai, S. Onuki, R. D. Kavthe, R. Kumashiro, N. Hiroshiba, T. Jin, N. Asao and K. Tanigaki, Phys. Opt., arXiv:1903.08869, 2019, https:// arxiv.org/abs/1903.08869.

7 I. D. W. Samuel and G. A. Turnbull, Chem. Rev., 2007, 107, 1272-1295.

8 S. Chénais and S. Forget, Polym. Int., 2012, 61, 390-406.

9 A. J. C. Kuehne and M. C. Gather, Chem. Rev., 2016, 116, 12823-12864.

10 C. Grivas and M. Pollnau, Laser Photonics Rev., 2012, 6, 419-462.

11 Y. Jiang, Y.-Y. Liu, X. Liu, H. Lin, K. Gao, W.-Y. Lai and W. Huang, Chem. Soc. Rev., 2020, 49, 5885-5944.

12 J. Gierschner and S. Y. Park, J. Mater. Chem. C, 2013, 1, 5818-5832.

13 H.-H. Fang, J. Yang, J. Feng, T. Yamao, S. Hotta and H.-B. Sun, Laser Photonics Rev., 2014, 8, 687-715.

14 J. Gierschner, S. Varghese and S. Y. Park, Adv. Opt. Mater., 2016, 4, 348-364.

15 R. Hibino, M. Nagawa, S. Hotta, M. Ichikawa, T. Koyama and Y. Taniguchi, Adv. Mater., 2002, 14, 119-122.

16 G. Kreiza, P. Baronas, E. Radiunas, P. Adomènas, O. Adomėnienė, K. Kazlauskas, J.-C. Ribierre, C. Adachi and S. Juršènas, Adv. Opt. Mater., 2017, 5, 1600823.

17 P. Baronas, G. Kreiza, M. Mamada, S. Maedera, P. Adomėnas, O. Adomėnienė, K. Kazlauskas, C. Adachi and S. Juršènas, Adv. Opt. Mater., 2019, 7, 1901670.

18 T. Oyamada, C. H. Chang, T. C. Chao, F. C. Fang, C. C. Wu, K. T. Wong, H. Sasabe and C. Adachi, J. Phys. Chem. C, 2007, 111, 108-115.

19 H. Nakanotani, M. Saito, H. Nakamura and C. Adachi, Appl. Phys. Lett., 2009, 95, 103307.

20 M. Morales-Vidal, P. G. Boj, J. M. Villalvilla, J. A. Quintana, Q. Yan, N.-T. Lin, X. Zhu, N. Ruangsupapichat, J. Casado, H. Tsuji, E. Nakamura and M. A. Diaz-Garcia, Nat. Commun., 2015, 6, 8458.

21 H. Nakanotani, S. Akiyama, D. Ohnishi, M. Moriwake, M. Yahiro, T. Yoshihara, S. Tobita and C. Adachi, Adv. Funct. Mater., 2007, 17, 2328-2335.

22 W. Zhang, Y. Yan, J. Gu, J. Yao and Y. S. Zhao, Angew. Chem., Int. Ed., 2015, 54, 7125-7129.

23 V. T. N. Mai, A. Shukla, M. Mamada, S. Maedera, P. E. Shaw, J. Sobus, I. Allison, C. Adachi, E. B. Namdas and S.-C. Lo, ACS Photonics, 2018, 5, 4447-4455.

24 B. K. Yap, R. Xia, M. Campoy-Quiles, P. N. Stavrinou and D. D. C. Bradley, Nat. Mater., 2008, 7, 376-380.

25 T. Aimono, Y. Kawamura, K. Goushi, H. Yamamoto, H. Sasabe and C. Adachi, Appl. Phys. Lett., 2005, 86, 071110.

26 H. Nakanotani, C. Adachi, S. Watanabe and R. Katoh, Appl. Phys. Lett., 2007, 90, 231109.

27 M. Mamada, T. Fukunaga, F. Bencheikh, A. S. D. Sandanayaka and C. Adachi, Adv. Funct. Mater., 2018, 28, 1802130.

28 Y. Oyama, M. Mamada, A. Shukla, E. G. Moore, S.-C. Lo, E. B. Namdas and C. Adachi, ACS Mater. Lett., 2020, 2, 161-167.
29 A. S. D. Sandanayaka, K. Yoshida, M. Inoue, C. Qin, K. Goushi, J.-C. Ribierre, T. Matsushima and C. Adachi, Adv. Opt. Mater., 2016, 4, 834-839.

30 A. S. D. Sandanayaka, T. Matsushima, F. Bencheikh, K. Yoshida, M. Inoue, T. Fujihara, K. Goushi, J.-C. Ribierre and C. Adachi, Sci. Adv., 2017, 3, e1602570.

31 T. W. Lee, O. O. Park, D. H. Choi, H. N. Cho and Y. C. Kim, Appl. Phys. Lett., 2002, 81, 424-426.

32 A. Rose, Z. G. Zhu, C. F. Madigan, T. M. Swager and V. Bulovic, Nature, 2005, 434, 876-879.

33 E. B. Namdas, M. Tong, P. Ledochowitsch, S. R. Mednick, J. D. Yuen, D. Moses and A. J. Heeger, Adv. Mater., 2009, 21, 799-802.

34 C. C. Wu, M. C. DeLong, Z. V. Vardeny and J. P. Ferraris, Synth. Met., 2003, 137, 939-941.

35 S. Varghese, S. K. Park, S. Casado, R. C. Fischer, R. Resel, B. Milian-Medina, R. Wannemacher, S. Y. Park and J. Gierschner, J. Phys. Chem. Lett., 2013, 4, 1597-1602.

36 H. Nakanotani, M. Saito, H. Nakamura and C. Adachi, Appl. Phys. Lett., 2009, 95, 033308.

37 G. P. Bartholomew, G. C. Bazan, X. Bu and R. J. Lachicotte, Chem. Mater., 2000, 12, 1422-1430.

38 S.-J. Yoon and S. Y. Park, J. Mater. Chem., 2011, 21, 8338-8346.

39 Y. Xu, K. Wang, Y. Zhang, Z. Xie, B. Zou and Y. Ma, J. Mater. Chem. C, 2016, 4, 1257-1262.

40 Y. Xu, Z. Xie, H. Zhang, F. Shen and Y. Ma, CrystEngComm, 2016, 18, 6824-6829.

41 B. Lu, Y. Zhang, X. Yang, K. Wang, B. Zou and D. Yan, J. Mater. Chem. C, 2018, 6, 9660-9666.

42 J. Shi, L. E. A. Suarez, S.-J. Yoon, S. Varghese, C. Serpa, S. Y. Park, L. Lüer, D. Roca-Sanjuán, B. Milián-Medina and J. Gierschner, J. Phys. Chem. C, 2017, 121, 23166-23183.

43 J. Han, J. You, X. Li, P. Duan and M. Liu, Adv. Mater., 2017, 29, 1606503.

44 J. S. Ramírez-Pradilla, C. Blanco-Tirado and M. Y. Combariza, ACS Appl. Mater. Interfaces, 2019, 11, 10975-10987.

45 T. Zhanga, G. Zhu, L. Lin, J. Mu, B. Ai, Y. Li and S. Zhuo, Org. Electron., 2019, 68, 264-270.

46 Y. Xu, H. Zhang, F. Li, F. Shen, H. Wang, X. Li, Y. Yu and Y. Ma, J. Mater. Chem., 2012, 22, 1592-1597.

47 X. Li, Y. Xu, F. Li and Y. Ma, Org. Electron., 2012, 13, $762-766$.

48 C.-W. Chang, C. J. Bhongale, C.-S. Lee, W.-K. Huang, C.-S. Hsu and E. W.-G. Diau, J. Phys. Chem. C, 2012, 116, 15146-15154.

49 J. Deng, J. Tang, Y. Xu, L. Liu, Y. Wang, Z. Xiec and Y. Ma, Phys. Chem. Chem. Phys., 2015, 17, 3421-3425.

50 J. Deng, Y. Xu, L. Liu, C. Feng, J. Tang, Y. Gao, Y. Wang, B. Yang, P. Lu, W. Yanga and Y. Ma, Chem. Commun., 2016, 52, 2370-2373.

51 C. Wang, Y. Li, Q. Xu and L. Luo, Opt. Mater., 2017, 72, 710-716.

52 J. Shi, S.-J. Yoon, L. Viani, S. Y. Park, B. Milián-Medina and J. Gierschner, Adv. Opt. Mater., 2017, 5, 1700340.

53 S. Hayashi, R. Hirai, S. Yamamoto and T. Koizumi, Chem. Lett. , 2018, 47, 1003-1005. 
54 Y.-X. Li, J.-X. Qiu, J.-L. Miao, Z.-W. Zhang and G.-X. Sun, J. Phys. Chem. C, 2015, 119, 2388-2398.

55 S. E. Estrada, C. Ochoa-Puentes and C. A. Sierra, J. Mol. Struct., 2017, 1133, 448-457.

56 S. Jeon, J. P. Lee and J.-M. Kim, J. Mater. Chem. C, 2015, 3, 2732-2736.

57 G. R. Desiraju and A. Gavezzotti, Acta Crystallogr., Sect. B: Struct. Sci., 1989, 45, 473-482.

58 K. Shoji, J. Nishida, D. Kumaki, S. Tokitoab and Y. Yamashita, J. Mater. Chem., 2010, 20, 6472-6478.

59 M. Martínez-Abadía, R. Giménez and M. Blanca Ros, Adv. Mater., 2017, 30, 1704161.
60 R. Kabe, H. Nakanotani, T. Sakanoue, M. Yahiro and C. Adachi, Adv. Mater., 2009, 21, 4034-4038.

61 D. Fichou, S. Delysse and J.M. Nunzi, Adv. Mater., 1997, 9, 1178-1181. 62 M. Polo, A. Camposeo, S. Tavazzi, L. Raimondo, P. Spearman, A. Papagni, R. Cingolani and D. Pisignano, Appl. Phys. Lett., 2008, 92, 083311.

63 M. Mamada, R. Komatsu and C. Adachi, ACS Appl. Mater. Interfaces, 2020, 12, 28383-28391.

64 C. Wang, H. Dong, W. Hu, Y. Liu and D. Zhu, Chem. Rev., 2012, 112, 2208-2267.

65 T. Yasuda, T. Goto, K. Fujita and T. Tsutsuia, Appl. Phys. Lett., 2004, 85, 2098-2100. 